\title{
The Potential Role of an Extended-Release, Abuse- Deterrent Oxycodone/Acetaminophen Fixed-Dose Combination Product for the Treatment of Acute Pain
}

\author{
Joseph V. Pergolizzi Jr. • Robert Taylor Jr. • Robert B. Raffa
}

To view enhanced content go to www.advancesintherapy.com Received: December 18, 2014 / Published online: May 31, 2015

(C) The Author(s) 2015. This article is published with open access at Springerlink.com

\section{ABSTRACT}

Acute pain, prevalent as part of postoperative and traumatic pain, is often sub-optimally or inadequately treated. Fixed-dose combination analgesic products that combine a reduced amount of opioid with a nonopioid analgesic

Electronic supplementary material The online version of this article (doi:10.1007/s12325-015-0213-5) contains supplementary material, which is available to authorized users.

J. V. Pergolizzi Jr.

Department of Medicine, Johns Hopkins University

School of Medicine, Baltimore, MD, USA

J. V. Pergolizzi Jr.

Department of Pharmacology, Temple University

School of Medicine, Philadelphia, PA, USA

J. V. Pergolizzi Jr.

Department of Anesthesiology, Georgetown

University School of Medicine, Washington, DC, USA

J. V. Pergolizzi Jr.

Association of Chronic Pain Patients, Houston, TX, USA

R. Taylor Jr. ( $₫)$

NEMA Research Inc., Bonita Springs, FL, USA

e-mail: robert.taylor.phd@gmail.com

R. B. Raffa

Department of Pharmaceutical Sciences, Temple University School of Pharmacy, Philadelphia, PA, USA such as acetaminophen (paracetamol) in a single tablet offer potential pharmacodynamic and/or pharmacokinetic benefits, and may also result in an opioid-sparing effect. A new analgesic product (XARTEMIS $^{\mathrm{TM}}$ XR, Mallinckrodt Brand Pharmaceuticals, Dublin, Ireland) combines oxycodone $(7.5 \mathrm{mg})$ with acetaminophen (325 $\mathrm{mg}$ ) in an immediaterelease/extended-release (ER) formulation that is indicated for the treatment of acute pain. The ER formulation of this product provides stable serum drug concentrations that in this case lasts $12 \mathrm{~h}$. Oxycodone/acetaminophen is a drug combination that offers safe and effective pain relief in a variety of acute pain syndromes such as postoperative pain. The combination formulation allows a smaller amount of oxycodone per tablet and the biphasic-layered matrix of the pill for ER may present obstacles to potential abusers. No opioid is totally abuse resistant, but the lower opioid content and tamper-resistant formulation of this product might discourage abuse. Clinicians must still be mindful of the acetaminophen part of this product in the patient's overall daily intake (in light of acetaminophen hepatotoxicity). The new product appears to provide an important 
new choice in the armamentarium against acute pain.

Keywords: Acute pain control; Extendedrelease analgesics; Fixed-dose combination products; Oxycodone/acetaminophen (paracetamol); Postoperative pain; Xartemis ${ }^{\circledR}$ XR

\section{INTRODUCTION}

Acute pain is prevalent and often under-treated $[1,2]$ that results in increased suffering and distress, delayed rehabilitation and healing, and may transition to chronic pain (a process known as chronification) [3, 4]. Acute pain may occur following surgical procedures, trauma, or illness. Even when acute pain is predictable and occurs in a controlled setting (such as inpatient surgery), pain is often lessthan-optimally treated. In a survey of 250 adults who had surgery as an in- or outpatient in the last 5 years, $82 \%$ reported at least some degree of pain in the period of up to 2 weeks after surgery; $21 \%$ and $18 \%$ of these respondents categorized the postsurgical pain as severe or extreme, respectively [5]. In a French survey among 750 adult patients $24 \mathrm{~h}$ following surgery, $87 \%$ reported postsurgical pain with half $(50.9 \%)$ categorizing that pain as severe [6]. A German multicenter study $(n=2252$ patients who underwent surgery or other procedure) found that $88 \%$ of patients were in pain $24 \mathrm{~h}$ after their treatment, with non-surgical patients experiencing slightly higher rates of undertreated pain [7]. In a survey of 50,869 patients with acute pain of various etiologies (surgery, trauma, postherpetic neuralgia, low back pain, and other conditions), $44 \%$ reported inadequate analgesia [8].
The pharmacological armamentarium for managing acute pain includes nonopioid agents, notably acetaminophen (paracetamol), nonsteroidal anti-inflammatory drugs (NSAIDs), and anticonvulsants [9], although their efficacy in acute pain is debatable; and opioids for moderate to severe or very severe pain. Risks and benefits attach to each of these agents. Acetaminophen has been associated with liver damage [10]. NSAIDs have been associated with gastrointestinal side effects and cardiovascular adverse events [11, 12]. Opioids are associated with potentially treatment-limiting side effects. In a survey of 50,869 patients with acute pain, $37 \%$ of those treated with a strong opioid discontinued their medication before pain resolved because of intolerable side effects [8]. Thus, the undertreatment of acute pain may sometimes be due to the fact an analgesic product was not tolerated, rather than the fact that no analgesics were prescribed.

\section{LONG-ACTING FORMULATIONS}

XARTEMIS $^{\mathrm{TM}}$ XR (previously known as MNK795, Mallinckrodt Brand Pharmaceuticals, Dublin, Ireland), is the first immediate-release (IR)/extended-release (ER) abuse-deterrent formulation comprised of a fixed-dose combination of oxycodone $(7.5 \mathrm{mg})$ plus acetaminophen $(325 \mathrm{mg}$ ) that is available on the market. While there are no consensus definitions for terms such as "long acting", "short acting", "immediate release", "controlled release", or "extended release" [13], it is generally accepted that short-acting opioids (e.g., morphine, oxycodone) have a duration of action of about $2-4 \mathrm{~h}$, while a long-acting opioid maintains therapeutic serum concentration for 12-24 h (e.g., methadone, tramadol) $[14,15]$. By this convention, 
XARTEMIS $^{\mathrm{TM}}$ XR would be classified as longacting, even though it has a short-acting component. Clinical intuition would hold that long-acting analgesics offer certain potential advantages: reduced pill burden, greater convenience [16], more sustained serum drug concentration [17], and reduction of "end-ofdose" phenomena or "analgesic gaps" between doses [18]. XARTEMIS ${ }^{\mathrm{TM}}$ XR was designed to incorporate rapidity of analgesic onset combined with long duration of action. The intended result is better overall pain control.

Analgesic effect is related to serum drug concentration; the minimum effective concentration (MEC) defines the level of serum drug level required to provide analgesia [19]. Thus, providing a consistent serum drug concentration above the MEC for a prolonged period of time may confer greater analgesia than a short-acting agent. A caveat is that headto-head studies comparing long-acting to shortacting analgesic agents are few and the evidence is still equivocal. For example, in a study of cancer patients treated with long-acting and short-acting opioids, patients in the long-acting opioid group had significantly lower pain intensity scores $(P=0.008)$ and better quality of life than patients in the short-acting opioid group [16], but other studies found long-acting and short-acting opioids conferred similar analgesic benefits [20, 21]. A double-blind clinical trial that compared ER oxycodone to IR fixed-dose oxycodone/acetaminophen analgesics in patients with osteoarthritis with chronic pain found similar pain control between agents, but the patients taking the ER product reported significantly better sleep quality [22]. In a randomized, double-blind study of patients with cancer pain, patients taking sustained-release oral morphine reported significantly less tiredness than those taking IR oral morphine [23].
Many opioid-related adverse events, such as respiratory depression, are dose related. The more constant serum concentration levels resulting from long-acting opioids avoid the peak-to-trough transitions of short-acting opioids, and have been thought to offer greater tolerability [13]. Evidence supporting reduced side effects in long-acting versus shortacting opioid agents, though, has been mixed $[14,21,22,24]$. Comparative studies of opioid analgesic agents are complicated by the fact that pain is subjective, variable, and that patients do not respond similarly to opioids; for instance, there is no clear evidence that any one opioid agent is clinically superior to the others, although individual patients may respond better to one than another.

There are reasons why prescribers might select long-acting analgesic agents over shortacting agents for their patients: long-acting formulations may provide analgesic benefit for 12-24 h [15]; long-acting agents may provide sufficiently long pain control to permit uninterrupted sleep; and long-acting agents reduce frequent dosing, which patients may prefer and which might improve compliance which, in turn, could improve analgesic relief. There appears to be widespread clinical acceptance of long-acting opioids, as evidenced by the fact that 23 million ER prescriptions were dispensed in the United States (US) in 2009 [25].

ER formulations are available for singleentity opioids, such as hydrocodone, hydromorphone, morphine, oxycodone, and tapentadol. Transdermal buprenorphine and transdermal fentanyl may also be considered long-acting single-entity opioid analgesics. Single-entity ER hydrocodone was cleared for market by the US Food and Drug Administration (FDA) under considerable controversy, in that its Advisory Panel 
recommended against approval [26-28]. XARTEMIS $^{\mathrm{TM}}$ XR is the only IR/ER formulation of a fixed-dose oxycodone/acetaminophen combination product on the market today.

\section{EFFICACY AND SAFETY OF THE OXYCODONE/ ACETAMINOPHEN FIXED-DOSE PRODUCT}

A fixed-dose combination analgesic is a product that combines two or more agents into a single tablet or capsule to offer additive or synergistic analgesic benefits, or reduce overall adverse effects (AEs) [29]. A further benefit of opioid/ nonopioid fixed-dose combination products is that they may provide analgesia using a lower dose of opioid, resulting in a so-called "opioidsparing effect" [30]. The synergistic combination of oxycodone plus acetaminophen shown in animal models has been reflected in safe and effective pain relief in many types of clinical pain syndromes [30], including low back pain [31], rheumatic conditions [32-34], postsurgical pain [35-37], pain following dental procedures [38], acute pain [39], and cancer pain [40].

XARTEMIS $^{\mathrm{TM}}$ XR was evaluated in a randomized, double-blind, placebo-controlled study of 266 bunionectomy patients [41]. Patients were administered four doses (2 tablets every $12 \mathrm{~h}$ ) of oxycodone/ acetaminophen ER product or placebo. The mean summed pain intensity difference at $48 \mathrm{~h}$ was $114.9( \pm 7.6)$ for the active group and $66.9( \pm 7.6)$ for the placebo group $(P<0.0001)$, with the treatment group achieving meaningful pain relief significantly sooner than the control patients. After the first $30 \mathrm{~min}$, the treatmentgroup patients had $\geq 30 \%$ pain intensity relief at all of the time points versus placebo. Placebo- group patients took more supplemental/rescue medication (i.e., ibuprofen, $400 \mathrm{mg}$ every $6 \mathrm{~h}$ ) over $48 \mathrm{~h}$ than did the active-group patients (4.64 vs. 2.91 doses, respectively, $P<0.0001$ ). More patients in the treatment than placebo group reported AEs $(53.6 \%$ vs. 21.5\%, respectively), but the rate of constipation was low $(4.2 \%$ vs. $3.1 \%$, respectively) which may have been attributable to the short duration of the study. Other AEs included nausea (30.7\% vs. $5.5 \%)$, dizziness (13.3\% vs. $1.2 \%)$, headache (9.6\% vs. $4.9 \%)$, skin disorders $(9.0 \%$ vs. $4.3 \%)$, vomiting $(9.0 \%$ vs. $0 \%)$, and somnolence $(3.6 \%$ vs. $0.6 \%)$.

In an open-label extension study of the above trial lasting at least 14 days, tolerability of XARTEMIS ${ }^{\mathrm{TM}}$ XR was consistent with that of an opioid product and AEs occurred in $43.8 \%$ of patients [42]. The most common AEs reported in this extension study were nausea (17.8\%), vomiting (7.5\%), and constipation (6.2\%).

In an analysis of 20 studies of XARTEMIS ${ }^{\mathrm{TM}}$ XR $(n=2641$ patients total), the number needed to treat for at least 50\% pain relief was $4.6(95 \%$ confidence interval, range 2.9-11) for singleentity oxycodone and 2.7 (95\% confidence interval, range 2.4-3.1) for oxycodone/ acetaminophen 10/650 mg (an IR product) [35].

\section{CONSIDERATIONS FOR THE USE OF ACETAMINOPHEN IN FIXED- DOSE PRODUCTS}

Acetaminophen is the most frequently consumed analgesic in the US [43, 44]. The FDA has launched various public health initiatives regarding this familiar drug's potential hepatotoxicity, and it recommends that adult doses be limited to no more than $4000 \mathrm{mg}$ per day, which is higher than the $3000 \mathrm{mg}$ maximum daily dose on current 
products marketed by McNeill Consumer Healthcare, a Johnson \& Johnson company $[45,46]$. Since this total daily dose is cumulative from all sources, the FDA further limits the dose of acetaminophen allowed in prescription combination products [47]. Despite these efforts, however, consumers may be unaware of potential acetaminophen toxicity or be unaware of all of the sources of acetaminophen in their medicine cabinets [48-50].

XARTEMIS $^{\mathrm{TM}}$ XR contains $325 \mathrm{mg}$ of acetaminophen per tablet, which falls within the new FDA requirements ( 2 tablets $=650 \mathrm{mg}$ acetaminophen, $\quad 4 \quad$ tablets $=1300 \mathrm{mg}$ acetaminophen/day). However, patient education is still necessary when prescribing a product that contains acetaminophen. Clinicians who prescribe a product containing acetaminophen should be diligent about informing patients about toxicity and dose limits.

The risk of hepatotoxicity was evaluated in a large retrospective cohort study of 1,228,356 adults taking either oxycodone/acetaminophen or hydrocodone/acetaminophen products compared to controls taking opioids only [51]. After adjusting for confounders, the opioid-only group did not exhibit a lower rate of hepatotoxicity-related hospitalizations at 12 months than did the groups taking oxycodone or hydrocodone combination products with acetaminophen. To date, there are no strong population-based data indicating that fixed-dose combination products containing acetaminophen elevate the patient's risk of hepatotoxicity-related hospitalization. Nevertheless, diligence must be exercised.

\section{DRUG DELIVERY TECHNOLOGY}

The XARTEMIS ${ }^{\mathrm{TM}}$ XR product was designed as a dual-layer product to allow for biphasic drug delivery as well as provide resistance to some tampering methods. A partial amount of the agents is released immediately for rapid onset of pain relief, followed by a gradual, sustained release of the remainder over $12 \mathrm{~h}$ [52]. Each tablet contains a release-controlling polymer that swells in the stomach, extending drug release. When taken as a single dose (two tablets, oxycodone/acetaminophen), the IR layer delivers approximately $3.75 / 325 \mathrm{mg}$ of oxycodone/acetaminophen followed by the release from the ER layer of approximately $11.25 / 325 \mathrm{mg}$ of oxycodone/acetaminophen.

The use of the polymer technology was evaluated in a phase I study to determine if food intake might affect the pharmacokinetic properties. A study of 48 health volunteers (men and women, ages 18-55 years, body mass indices ranging from 19 to 30) in an openlabel, single-center, three-period, six-sequence, crossover study over 13 weeks found small differences in maximum serum concentration $\left(C_{\max }\right)$ for oxycodone and acetaminophen in fed versus fasted subjects, but these differences were deemed not large enough to have clinical relevance [53]. The area-under-the-time curve (AUC) 0 to infinity and $\mathrm{AUC}_{\mathrm{O}-\mathrm{t}}$ were nearly identical in fed and fasted subjects. The bioavailability of both oxycodone and acetaminophen was within the acceptable limit of $80-125 \%$ for the $90 \%$ confidence interval for the geometric least squares mean ratio for AUC and $C_{\max }$ for high-fat state versus fasted state. Thus, it does not appear that the level of food intake will affect the product's 
pharmacokinetics; the package insert indicates dosing without regard to food [54].

\section{THE POTENTIAL ROLE OF EXTENDED-RELEASE COMBINATION PRODUCTS FOR CHRONIC PAIN SYNDROMES}

XARTEMIS $^{\mathrm{TM}} \mathrm{XR}$ is indicated for acute pain [54]. Although many guidelines recommend opioid analgesics for chronic pain conditions [55-57], including for geriatric patients [58, 59], the use of opioids for chronic nonmalignant pain remains controversial [60-62]. In a retrospective review, fixed-dose IR oxycodoneacetaminophen combination products were the most frequently prescribed drugs for patients with chronic noncancer pain [63], and they have demonstrated safety and efficacy in the treatment of chronic pain syndromes [30, 32, 34]. It must be noted that this is off-label use and the authors are not advocating such use.

\section{ABUSE POTENTIAL OF EXTENDED- RELEASE OXYCODONE/ ACETAMINOPHEN}

In 2009, the FDA stated that there was a need for a class-wide Risk Evaluation and Mitigation Strategy (REMS) for ER opioids, and such was proposed the following year and approved in 2012 [64]. A key consideration for REMS is that ER single-entity opioid formulations contain more opioid per dosage unit than do comparable IR formulations, and larger doses are thought to be associated with an elevated risk of abuse [65]. Moreover, long-acting singleentity opioids have been associated with higher rates of overdose [66]. There is no comparable class-wide REMS for IR opioids, which may have led to the otherwise unsupported notion that IR opioids products are somehow "safer" than ER opioids. Fixed-dose combination products can contain a relatively small amount of opioid, which in theory is less attractive to potential abusers. Currently XARTEMIS ${ }^{\mathrm{TM}}$ XR does not have a REMS requirement.

The abuse potential for long-acting compared to short-acting opioid formulations remains to be elucidated. For instance, opioid abusers tend to prefer the effects of IR products compared to ER products [67], but they may opt to abuse ER products if they can extract the drug, because ER single-entity products contain larger quantities of opioid. Since opioids are often abused by people who are not patients, but by those who obtain prescription pain relievers from family or friends [68], opioid selection is often based on what is available.

The biphasic-layered structure of XARTEMIS $^{\mathrm{TM}}$ XR may resist or deter potential abuse. Abuse-deterrent formulations represent an important effort to reduce opioid abuse $[69,70]$, but long-term longitudinal studies are needed to ascertain their true impact on opioid abuse. The new product contains a smaller amount of oxycodone per tablet $(7.5 \mathrm{mg})$ and that appears to be relatively difficult to extract due to the incorporation of the PolyOx ${ }^{\mathrm{TM}}$ (The Dow Chemical Company Midland, MI, USA) polymer [71]. The acetaminophen content of the tablets may deter some abusers, who may be concerned about the potential hepatotoxic risk of high doses.

Although the combination of acetaminophen with an opioid may make the drug less attractive to abusers, combination products may still be abused and, in such cases, the abuser may suffer from acetaminophen poisoning. For example, patients who crush combination products to "snort" or to inhale them may absorb potentially toxic concentrations of 
acetaminophen $[72,73]$. There is relatively little research into the pharmacokinetics of nasal acetaminophen.

\section{CLINICAL PERSPECTIVE}

XARTEMIS $^{\mathrm{TM}} \mathrm{XR}$ is the only available longacting formulation of the frequently prescribed combination of oxycodone and acetaminophen. While IR oxycodone/ acetaminophen and other opioid/nonopioid fixed-dose products are available, they are all short-acting formulations. But pain may last for several days or weeks before it diminishes or resolves, and an ER formulation allows for more convenient dosing, decreases the pill burden, and offers more steady serum concentrations than do IR products. It is easy to speculate on potential advantages of this sort of ER product: it may allow for patients to get a full night's sleep, it may improve their ability to resume everyday activities with prolonged pain relief, and it may be better accepted by patients who often dislike having to take pills every 4-6 h. The opioid-sparing benefits of this combination product provide analgesic relief with a relatively small quantity of opioid. Thus, there are some immediate reasons to welcome this product.

However, ER opioid formulations do have some drawbacks. For example, ER formulations are generally not appropriate to treat breakthrough pain. If one was to treat breakthrough pain with ER formulations, increasing the dose, as is generally the practice, exposes the patient to more than necessary medication, which can lead to more sedation and side effects. Appropriate treatment depends on the type and duration of breakthrough pain and generally includes short-acting opioids such as oxycodone and morphine with fentanyl formulations used for very short duration, rapid-onset breakthrough pain. Another drawback is the potential for abuse. While public health initiatives have done much to decrease opioid abuse [74, 75], it remains a serious problem. For some outside the clinical community, eliminating or vastly restricting opioid analgesics seems like a viable solution to prescription analgesic abuse, but this would leave much moderate-to-severe pain untreated. Responsible prescribing involves balanced and measured steps. As a Schedule II controlled substance, this new oxycodone/ acetaminophen product will be closely regulated and it lacks some of the features that make opioid analgesics particularly "likeable" in the eyes of potential abusers. No opioid analgesic is totally abuse-proof, but this formulation might be less likely to become a prime target for potential abusers. However, much work is still necessary on the part of clinicians to educate patients and their caregivers and families about the appropriate use of all opioid formulations and potential for misuse of opioid therapy.

Long-acting oxycodone/acetaminophen seems to be an important new option. It might offer equianalgesic benefits to patients with acute pain without exposing them to the greater quantity of opioids contained in singleentity opioid therapy. It will offer more stable serum concentrations, and its convenient dosing might improve patient adherence.

\section{CONCLUSION}

To the armamentarium for pain control has been added a long-acting fixed-dose combination product of oxycodone/acetaminophen (7.5/ $325 \mathrm{mg}), \mathrm{XARTEMIS}^{\mathrm{TM}} \mathrm{XR}$, which is indicated for the management of moderate to severe acute pain. The synergistic combination of oxycodone 
with acetaminophen demonstrated in animal models is well established as being safe and effective in numerous painful conditions, including postsurgical and posttraumatic pain. The new long-acting formulation should offer more stable serum drug concentrations than short-acting formulations and provide $12 \mathrm{~h}$ or more of pain relief. Its abuse potential may be less because of the lower amount of oxycodone per tablet and the difficulty associated with extracting it. As usual, good clinical practice dictates individualized patient care and counseling patients about potential AEs, acetaminophen toxicity and dose limitations, and potential for opioid misuse and abuse.

\section{ACKNOWLEDGMENTS}

No funding or sponsorship was received for this study or publication of this article. The authors acknowledge editorial support from Jo Ann LeQuang of LeQ Medical who was paid directly by the authors. All named authors meet the International Committee of Medical Journal Editors (ICMJE) criteria for authorship for this manuscript, take responsibility for the integrity of the work as a whole, and have given final approval for the version to be published. During the peer review process, the manufacturer of the agent under review was offered an opportunity to comment on the article. Changes resulting from comments received were made by the authors based on their scientific and editorial merit.

Conflict of interest. At times, Dr. Pergolizzi, Dr. Raffa, and Dr. Taylor act as consultants, researchers and/or lecturers for various pharmaceutical companies, but received no financial support related to this manuscript.
Compliance with ethics guidelines. This article is based on previously conducted studies and does not involve any new studies of human or animal subjects performed by any of the authors.

Open Access. This article is distributed under the terms of the Creative Commons Attribution Noncommercial License which permits any noncommercial use, distribution, and reproduction in any medium, provided the original author(s) and the source are credited.

\section{REFERENCES}

1. Rockett M, Simpson G, Crossley R, Blowey S. Characteristics of pain in hospitalized medical patients, surgical patients, and outpatients attending a pain management centre. $\mathrm{Br} \mathrm{J}$ Anaesth. 2013;110(6):1017-23.

2. Lin RJ, Reid MC, Chused AE, Evans AT. Quality assessment of acute inpatient pain management in an academic health center. Am J Hosp Palliat Care. 2014. doi:10.1177/1049909114546545.

3. Buchheit T, Van de Ven T, Shaw A. Epigenetics and the transition from acute to chronic pain. Pain Med. 2012;13(11):1474-90.

4. Apkarian AV, Baliki MN, Farmer MA. Predicting transition to chronic pain. Curr Opin Neurol. 2013;26(4):360-7.

5. Apfelbaum JL, Chen C, Mehta SS, Gan TJ. Postoperative pain experience: results from a national survey suggest postoperative pain continues to be undermanaged. Anesth Analg. 2003;97(2):534-40 (table of contents).

6. Fletcher D, Fermanian C, Mardaye A, Aegerter P, (SFAR) PaRACotFAaICS. A patient-based national survey on postoperative pain management in France reveals significant achievements and persistent challenges. Pain. 2008;137:441-51.

7. Maier C, Nestler N, Richter $\mathrm{H}$, et al. The quality of pain management in German hospitals. Dtsch Arztebl Int. 2010;107(36):607-14.

8. Moskovitz B, Benson CJ, Patel AA, et al. Analgesic treatment of moderate-to-severe acute pain in the 
United States: patients' perspectives in the physicians partnering against pain (P3) survey. J Opioid Manag. 2011;7(4):277-86.

9. Wiffen P, Collins S, McQuay H, Carroll D, Jadad A, Moore A. Anticonvulsant drugs for acute and chronic pain. Cochrane Database Syst Rev. 2005(3):CD001133.

10. Brune K, Hinz B, Otterness I. Aspirin and acetaminophen: should they be available over the counter? Curr Rheumatol Rep. 2009;11(1):36-40.

11. Dajani EZ, Islam K. Cardiovascular and gastrointestinal toxicity of selective cyclooxygenase-2 inhibitors in man. J Physiol Pharmacol. 2008;59(Suppl 2):117-33.

12. Taylor R Jr, Lemtouni S, Weiss K, Pergolizzi JV Jr. Pain management in the elderly: an FDA safe use initiative expert panel's view on preventable harm associated with NSAID therapy. Curr Gerontol Geriatr Res. 2012;2012:196159.

13. Amabile C, Bowman B. Overview of oral modifiedrelease opioid products for the management of chronic pain. Ann Pharmacother. 2006;409:1327-35.

14. Rauck RL. What is the case for prescribing longacting opioids over short-acting opioids for patients with chronic pain? A critical review. Pain Pract. 2009;9(6):468-79.

15. McCarberg B, Barkin R. Long-acting opioids for chronic pain: pharmacotherapeutic opportunities to enhance compliance, quality of life, and analgesia. Am J Ther. 2001;8:181-6.

16. Ferrell B, Wisdom C, Wenzl C, Brown J. Effects of controlled-release morphine on quality of life for cancer pain. Oncol Nurs Forum. 1989;16:521-6.

17. Sullivan M. Will data destroy our faith in longacting opioids? Pain Manag Nurs. 2014;155(5):881-8.

18. Pergolizzi JV Jr, Mercadante S, Echaburu AV, et al. The role of transdermal buprenorphine in the treatment of cancer pain: an expert panel consensus. Curr Med Res Opin. 2009;25(6):1517-28.

19. Gourlay G. Sustained relief after chronic pain. Pharmacokinetics of sustained release morphine. Clin Pharmacokinet. 1998;35:173-90.

20. Arkinstall W, Goughnour B, White J, Stewart J. Control of severe pain with sustained-release morphine tablets $\mathrm{v}$. oral morphine solution. CMAJ. 1989;140:653-7.
21. Hale M, Fleischmann RM, Salzman RT, et al. Efficacy and safety of controlled-release versus immediate-release oxycodone: randomized, double-blind evaluation in patients with chronic back pain. Clin J Pain. 1999;15:179-83.

22. Caldwell JR, Hale ME, Boyd RE, et al. Treatment of osteoarthritis pain with controlled release oxycodone or fixed combination oxycodone plus acetaminophen added to nonsteroidal antiinflammatory drugs: a double blind, randomized, multicenter, placebo controlled trial. J Rheumat. 1999;26(4):862-9.

23. Klepstad P, Kaasa S, Jystad A, Hval B, Borchgrevink $P$. Immediate- or sustained-release morphine for dose finding during start of morphine to cancer patients: a randomized, double-blind trial. Pain Manag Nurs. 2003;101:193-8.

24. Chou R, Clark E, Helfand M. Comparative efficacy and safety of long-acting oral opioids for chronic non-cancer pain: a systematic review. J Pain Symptom Manag. 2003;26(5):1026-48.

25. Governale L. Outpatient prescription opioid utilization in the U.S., years 2000-2009. Rockville: Food \& Drug Administration; 2010. http://www. fda.gov.ezproxy.welch.jhmi.edu/downloads/Adviso ryCommittees/CommitteesMeetingMaterials/Drugs/ DrugSafetyandRiskManagementADvisoryCommittee/ UCM220950.pdf. Accessed Nov 8, 2014.

26. Gould HJ 3rd, Paul D. Hydrocodone extendedrelease: pharmacodynamics, pharmacokinetics and behavioral pharmacology of a controversy. Pharmacol Res. 2015;91:99-103.

27. Manchikanti L, Atluri S, Candido KD, et al. Zohydro approval by food and drug administration: controversial or frightening? Pain Physician. 2014;17(4):E437-50.

28. Olsen Y, Sharfstein JM. Chronic pain, addiction, and Zohydro. $\mathrm{N}$ Engl J Med. 2014;370(22):2061-3.

29. Raffa RB. Pharmacology of oral combination analgesics: rational therapy for pain. J Clin Pharm Ther. 2001;26(4):257-64.

30. Gatti A, Sabato E, Di Paolo AR, Mammucari M, Sabato AF. Oxycodone/paracetamol: a low-dose synergic combination useful in different types of pain. Clin Drug Investig. 2010;30(Suppl 2):3-14.

31. Gammaitoni AR, Galer BS, Lacouture P, Domingos J, Schlagheck T. Effectiveness and safety of new oxycodone/acetaminophen formulations with reduced acetaminophen for the treatment of low back pain. Pain Med. 2003;4(1):21-30. 
32. Raffaeli W, Pari C, Corvetta A, et al. Oxycodone/ acetaminophen at low dosage: an alternative pain treatment for patients with rheumatoid arthritis. J Opioid Manag. 2010;6(1):40-6.

33. Gatti A, Sabato AF, Carucci A, Bertini L, Mammucari M, Occhioni R. Adequacy assessment of oxycodone/paracetamol (acetaminophen) in multimodal chronic pain : a prospective observational study. Clin Drug Investig. 2009;29(Suppl 1):31-40.

34. Corsinovi L, Martinelli E, Fonte G, et al. Efficacy of oxycodone/acetaminophen and codeine/ acetaminophen vs. conventional therapy in elderly women with persistent, moderate to severe osteoarthritis-related pain. Arch Gerontol Geriatr. 2009;49(3):378-82.

35. Gaskell H, Derry S, Moore RA, McQuay HJ. Single dose oral oxycodone and oxycodone plus paracetamol (acetaminophen) for acute postoperative pain in adults. Cochrane Database Syst Rev. 2009(3):CD002763.

36. Edwards JE, Moore RA, McQuay HJ. Single dose oxycodone and oxycodone plus paracetamol (acetaminophen) for acute postoperative pain. Cochrane Database Syst Rev. 2000(4):CD002763.

37. Kogan A, Medalion B, Raanani E, et al. Early oral analgesia after fast-track cardiac anesthesia. Can J Anaesth. 2007;54(4):254-61.

38. Chang DJ, Desjardins PJ, Bird SR, et al. Comparison of rofecoxib and a multidose oxycodone/ acetaminophen regimen for the treatment of acute pain following oral surgery: a randomized controlled trial. Curr Med Res Opin. 2004;20(6):939-49.

39. Lovell SJ, Taira T, Rodriguez E, Wackett A, Gulla J, Singer AJ. Comparison of valdecoxib and an oxycodone-acetaminophen combination for acute musculoskeletal pain in the emergency department: a randomized controlled trial. Acad Emerg Med. 2004;11(12):1278-82.

40. Sima L, Fang WX, Wu XM, Li F. Efficacy of oxycodone/paracetamol for patients with bonecancer pain: a multicenter, randomized, doubleblinded, placebo-controlled trial. J Clin Pharm Ther. 2012;37(1):27-31.

41. Singla N, Barrett T, Sisk L, Kostenbader K, Young J, Giuliani M. A randomized, double-blind, placebocontrolled study of the efficacy and safety of MNK-795, a dual-layer, biphasic, immediaterelease and extended-release combination analgesic for acute pain. Curr Med Res Opin. 2014;30(3):349-59.
42. Singla N, Barrett T, Sisk L, Kostenbader K, Young J. Assessment of the safety and efficacy of extendedrelease oxycodone/acetaminophen, for 14 days postsurgery. Curr Med Res Opin. 2014;30(12):2571-8

43. Kaufman D, Kelly J, Rosenberg L, Anderson T, Mitchell A. Recent patterns of medication use in the ambulatory adult population of the United States: the Slone survey. JAMA. 2002;287(3):337-44.

44. Vernacchio L, Kelly J, Kaufman D, Michell A. Medication use among children $<12$ years of age in the United States: results from the Slone Survey. Pediatrics. 2009;124:446-54.

45. Kuehn B. FDA focuses on drugs and liver damage: labeling and other changes for acetaminophen. JAMA. 2009;302:369-71.

46. Krenzelok E, The FDA. Acetaminophen advisory committee meeting-what is the future of acetaminophen in the United States? The perspective of a committee member. Clin Toxicol. 2009;47:784-9.

47. DeDea L. FDA limits acetaminophen; risk of death with tigecycline. JAAPA. 2012;25:16.

48. Stumpf J, Skyles A, Alaniz C, Erickson S. Knowledge of appropriate acetaminophen doses and potential toxicities in an adult clinic population. J Am Pharm Assoc. 2007; 47:35-41.

49. Hornsby L, Whitley H, Hester E, Thompson MM, Donaldson A. Survey of patient knowledge related to acetaminophen recognition, dosing, and toxicity. J Am Pharm Assoc. 2010;50:485-9.

50. Herndon C, Dankenbring D. Patient perception and knowledge of acetaminophen in a large family medicine service. J Pain Palliat Care Pharmacother. 2014;28:109-16.

51. Duh MS, Vekeman F, Korves C, et al. Risk of hepatotoxicity-related hospitalizations among patients treated with opioid/acetaminophen combination prescription pain medications. Pain Med. 2010;11(11):1718-25.

52. Extended-release oxycodone and acetaminophen. Xartemis XR. Med Lett Drugs Ther. 2014;56(1447):59-60.

53. Devarakonda K, Morton T, Margulis R, Giuliani M, Barrett T. Pharmacokinetics and bioavailability of oxycodone and acetaminophen following singledose administration of MNK-795, a dual-layer biphasic IR/ER combination formulation, under fed and fasted conditions. Drug Des Devel Ther. 2014;8:1125-34. 
54. Mallinckrodt I. XARTEMIS XR oxycodone hydrochloride and acetaminophen tablet, highlights of prescribing information. Hazelwood: Mallinckrodt Brand Pharmaceuticals Inc; 2014.

55. Zhang W, Doherty M, Arden N, et al. EULAR evidence based recommendations for the management of hip osteoarthritis: report of a task force of the EULAR Standing Committee for International Clinical Studies Including Therapeutics (ESCISIT). Ann Rheum Dis. 2005;64(5):669-81.

56. Zhang W, Doherty $M$, Leeb BF, et al. EULAR evidence based recommendations for the management of hand osteoarthritis: report of a Task Force of the EULAR Standing Committee for International Clinical Studies Including Therapeutics (ESCISIT). Ann Rheum Dis. 2007;66(3):377-88.

57. Zhang W, Moskowitz RW, Nuki G, et al. OARSI recommendations for the management of hip and knee osteoarthritis, Part II: OARSI evidence-based, expert consensus guidelines. Osteoarthr Cartil. 2008;16(2):137-62.

58. American Geriatrics Society. AGS Clinical Practice Guideline: pharmacological management of persistent pain in older persons. New York: American Geriatrics Society; 2013. http://www. americangeriatrics.org/health_care_professionals/ clinical_practice/clinical_guidelines_recommenda tions/persistent_pain_executive_summary. Cited Dec 14, 2013.

59. Pergolizzi J, Boger RH, Budd K, et al. Opioids and the management of chronic severe pain in the elderly: consensus statement of an International Expert Panel with focus on the six clinically most often used World Health Organization Step III opioids (buprenorphine, fentanyl, hydromorphone, methadone, morphine, oxycodone). Pain Pract. 2008;8(4):287-313.

60. Manchikanti L, Atluri S, Hansen H, et al. Opioids in chronic noncancer pain: have we reached a boiling point yet? Pain Physician. 2014;17(1):E1-10.

61. Manchikanti L, Benyamin R, Datta S, Vallejo R, Smith H. Opioids in chronic noncancer pain. Expert Rev Neurother. 2010;10(5):775-89.

62. Manchikanti L, Benyamin RM. Long-term opioid therapy. Pain Pract. 2009;9(2):164 (author reply).

63. DeRemer CE, Fleming VH, Brown S, May JR. Evaluation of pain management documentation. S Med J. 2011;104(9):629-33.

64. Stanos S. Evolution of opioid risk management and review of the classwide REMS for extended- release/long-acting opioids. Phys Sportsmed. 2012;40(4):12-20.

65. Mercadante S, Craig D, Giarratano A. US food and drug administration's risk evaluation and mitigation strategy for extended-release and longacting opioids: pros and cons, and a European perspective. Drugs. 2012;72(18):2327-32.

66. Braden JB, Russo J, Fan MY, Edlund MJ, Martin BC, DeVries A, et al. Emergency department visits among recipients of chronic opioid therapy. Arch Intern Med. 2010;170(16):1425-32.

67. Morton T, Kostenbader K, Montgomery J, Devarakonda K, Barrett T, Webster L. Comparison of subjective effects of extended-release versus immediate-release oxycodone/acetaminophen tablets in healthy nondependent recreational users of prescription opioids: a randomized trial. Postgrad Med. 2014;126(4):20-32.

68. Peppin JF, Coleman JJ, Kirsh KL. Issues and critiques of the forthcoming risk evaluation and mitigation strategy (REMS) for opioids in pain management. Issues Law Med. 2011;27(2):91-119.

69. Pergolizzi JV Jr, Lequang JA. Abuse-deterrent formulations of opioid analgesics. Pain Pract. 2014;14(3):204-6.

70. Schaeffer T. Abuse-deterrent formulations, an evolving technology against the abuse and misuse of opioid analgesics. J Med Toxicol. 2012;8(4):400-7.

71. Mallinckrodt, editor. Evaluation of the tamperresistant properties of MNK-795 controlled-release oxycodone/acetaminophen tablets (CR OC/APAP). Las Vegas: PAINWeek; 2013.

72. Reid N, Mazer-Amirshahi M, Clancy C, James L, van den Anker J. Elevated acetaminophen concentration measured after nasal insufflation of Percocet $^{\circledR}$. J Emerg Med. 2013;45(5):683-5.

73. Rosenbaum CD, Boyle KL, Boyer EW. Nasopharyngeal necrosis after chronic opioid (oxycodone/acetaminophen) insufflation. J Med Toxicol. 2012;8(2):240-1.

74. Alvarez L. Florida shutting 'pill mill' clinics. The New York Times. Sect. U.S.; 2011. Aug 31, 2011.

75. Reisman RM, Shenoy PJ, Atherly AJ, Flowers CR. Prescription opioid usage and abuse relationships: an evaluation of state prescription drug monitoring program efficacy. Subst Abuse. 2009;3:41-51. 